\title{
Design, development and testing of the JTech bolt for use in static, quasi-static and dynamic domains
}

\author{
T. Roberts Jennmar Australia Pty Ltd, Australia
}

A. Dodds Jennmar Australia Pty Ltd, Australia

\begin{abstract}
Designing a rock reinforcement element requires knowledge of geomechanical behaviour, interaction of the reinforcement element with rock mass, and the element's mechanistic response in static and dynamic environments. Using this knowledge, the JTech bolt was developed and subjected to a thorough program to test, gather data and validate the bolt performance in varying domains. By conducting finite element (FE) modelling, the simulation reviews the JTech bolt design evaluating the effects of threadbar geometric variation, threadbar and nut engagement results under high stress, coating friction response and effects of thread tolerance extremes on the failure mode. These results determine safety factors, tolerances and quality management criteria. Once manufactured, in situ system testing, laboratory and underground short encapsulation testing, resin mixing testing, double shear testing and dynamic testing at varying velocity and mass, determine the system's capacity and effectiveness in static, quasi-static and dynamic mining environments. In this paper, the process and results are described.
\end{abstract}

\section{Introduction}

Rock reinforcement design and the support elements used are just one requirement that comprises a completed ground support system. Once the failure mechanisms are determined, using the various design methods available to the engineer, the ground support system can be designed to stabilise the excavation and manage risk.

Due to the complexity of many rock reinforcement designs, the demand on the ground support system requires a greater level of data to ensure that the support system meets the design requirements and the engineer has satisfactory data available for the ground support design to meet the risk and legislative requirements associated with the excavation design.

This paper describes the processes and steps undertaken to design, test and validate the JTech bolt support system providing confidence in the data used by engineers in their ground support designs. The framework used to complete these test processes is determined by understanding the application for the JTech bolt and utilising or developing processes to test the element.

\section{Rock reinforcement element design}

The approach for element design is determined by its application. Whether the element is to be designed for use in static, quasi-static or dynamic geotechnical domains or required for specific application or ground condition, the design and data requirements must be appropriate for its application. Once the application is identified, the element design must consider the following:

- Relevant standards and legislation.

- Patent application if applicable.

- High volume manufacturing potential.

- Potential safety and environmental impacts. 
- Can specification and tolerance be controlled?

- Can the element be manufactured cost effectively?

- Is there large capital investment required to develop, manufacture and market the element?

- Manufacturing equipment design.

- Ease of installation and can the element be installed with existing installation equipment?

- Compatibility with other products and ground support systems?

Once the above process is followed and approved, a prototype can be developed and validated by testing to confirm the JTech bolt design.

\section{$3 \quad$ JTech bolt element design}

The JTech bolt was designed using the above considerations and developed to have application in static mining environments. With many static mining domains now affected by squeezing or bursting ground conditions, this necessitates dynamic testing processes to be completed to understand the JTech bolts' response under dynamic loading conditions.

The JTech bar, shown in Figure 1, is a thread deformed bar having a continuous hot-rolled pattern of threadlike deformations along the entire length, which allow nuts and couplers to thread onto the bar at any point. The JTech thread deformed bar is manufactured and tested in compliance with the chemical and mechanical property requirements of specification AS 4671-2001 and AS 1391, Grade HSCC500.

The HSCC500 bar has a minimum tensile strength to yield strength ratio of 1.08 and Uniform Elongation of $5 \%$, exceeding the $\mathrm{N}$ Class (normal ductility) requirements in AS 3600-2001 and reinforcing steel materials standard, AS 4671-2001. The HSCC500 bar is manufactured using the TEMPCORE process, which results in reinforcing steel with a carbon equivalent limit of 0.39-0.44 max. TEMPCORE produces a high strength rebar, with a tough outer skin and ductile core, providing exceptional toughness and ductility, a requirement for a ground support element to be used in varying geotechnical domains (ACRS compliance, 2007).
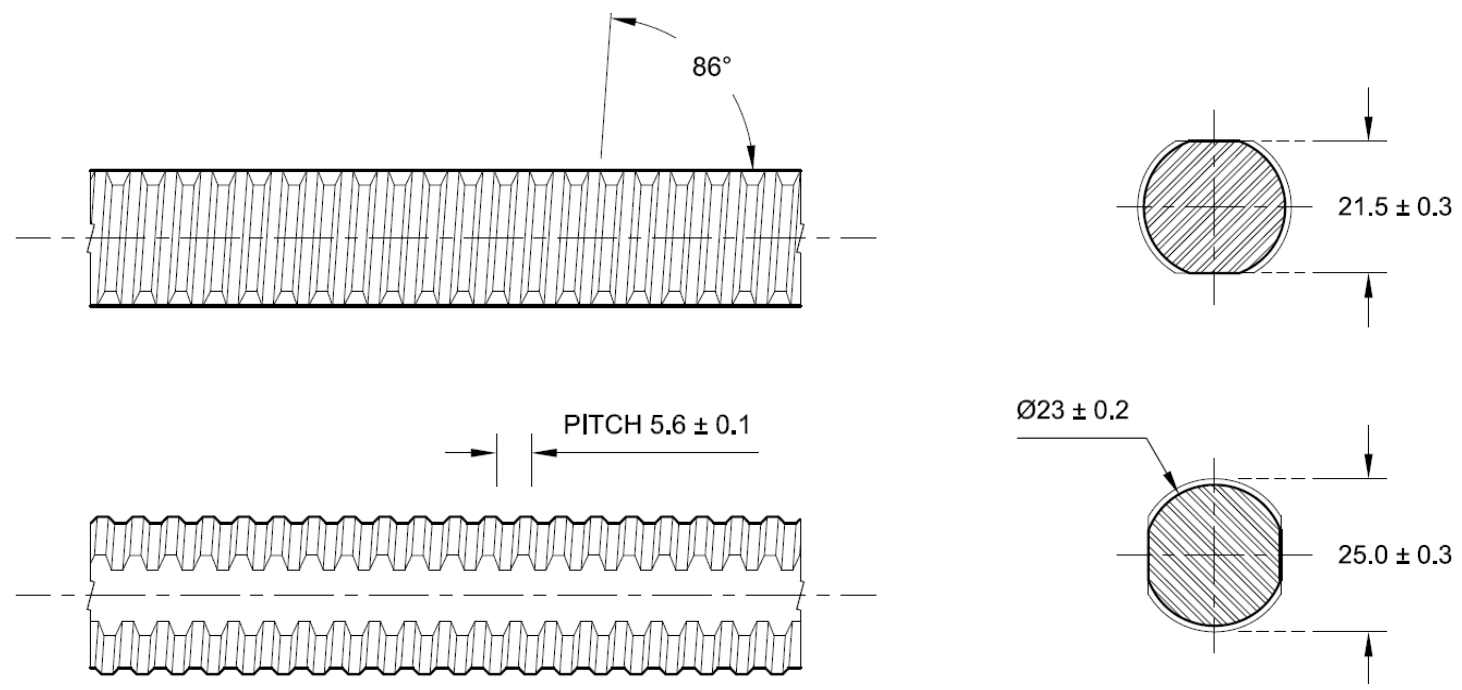

Figure 1 The JTech bar profile and end view

The JTech bolt has two patents granted being:

1. Patent International Publication Number WO 2009/094725 A1; Title, Rock Bolt Assembly.

2. Patent Australian Publication Number 2012100578; Title, Rock Bolt Assembly. 


\subsection{FE modelling of the JTech bar and nut engagement}

A study using FE modelling has been conducted to simulate the effects of thread tolerance, thread shape, engagement lengths and materials, to further confirm design parameters, thread performance and tolerance for quality control/quality assurance.

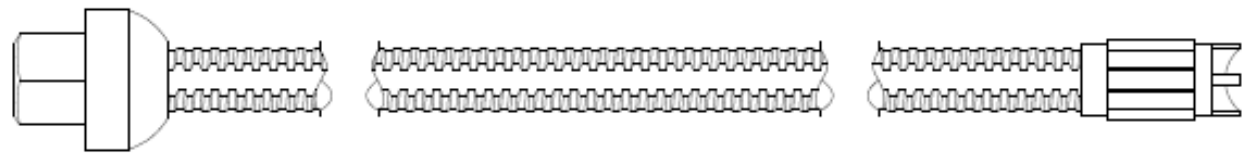

Figure 2 The JTech bolt in complete view, with patented resin capsule shredder mixing device. A study using FE modelling simulates thread performance, nut/bolt engagement capacity and tolerance extremes

The study framework aims to develop an understanding of the thread interactions of the JTech bar and nut. To provide a controlled and defined approach, the thread has been evaluated within the limits of set tolerances, to determine tolerance extremes, which will have the greatest effect on the stresses in the thread. The FE simulations compare the JTech bar and nut effective arc length, thread root radius, thread crown length, thread crest shape and the minimum and maximum core/rib dimension extremes.
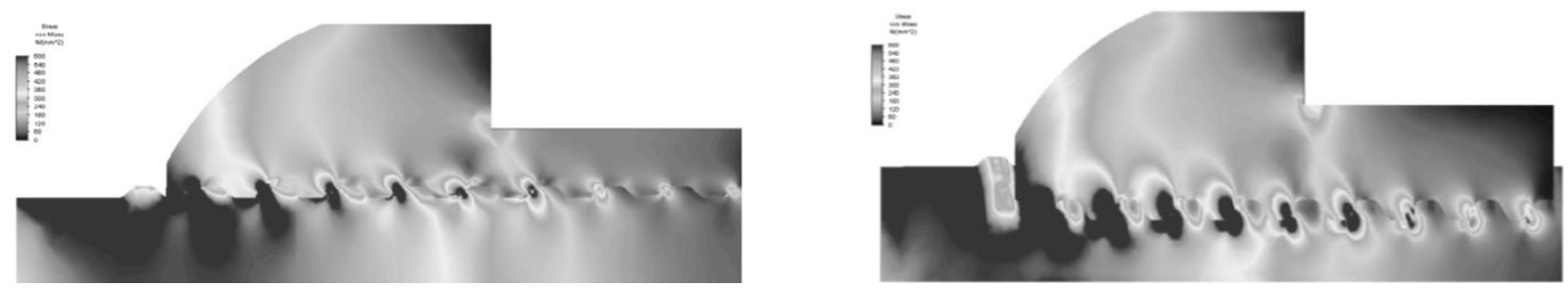

(a)

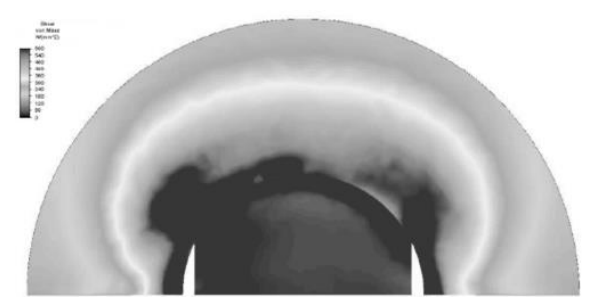

(b)
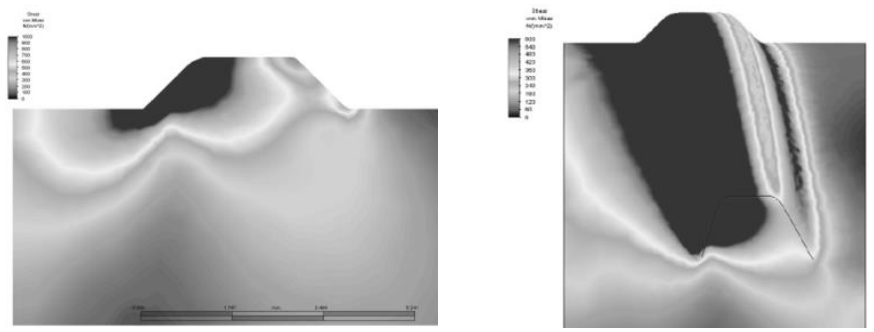

(c)

Figure 3 The JTech bolt FE simulation showing examples exploring the effects of thread tolerance, profile, shape and bar/nut engagement; (a) Simulation cut-away sections of the nut and bar engagement with images limited to show stress between 0 and $600 \mathrm{MPa}$; (b) Top down first thread simulation of the nut and bar engagement with images limited to show stress between 0 and $600 \mathrm{MPa}$; (c) The simulations give a comparison of stress through the centre and along the thread with images limited to show stress between 0 and $600 \mathrm{MPa}$

The FE simulations in Figure 3 are limited to show stress between 0 and $600 \mathrm{MPa}$. The simulations did not find a mechanism of early failure of the thread before the JTech bar failed. This is an important step, eliminating the likelihood of thread failure whilst the JTech bar and nut thread is within the specified tolerance. Simulations outside of the set tolerance showed increased stresses around the thread, although the bar should still fail first. To further reinforce the results from the FE simulations, analytical calculations were conducted which confirm that the nut does not fail prematurely. These calculations determine the length of engagement and arc length of available thread (found using graphical means), and the actual minimum length of engagement was calculated. 


\subsection{Quality assurance and quality control of receiving bar}

A materials test report is received from a bar supplier, reporting the chemical and physical properties of the specified heat. Reporting is in accordance to AS 1391-2007 Metallic materials - tensile testing at ambient temperature.

The test process involves setting the bar in the in-house $100 \mathrm{t}$ test machine, which is calibrated annually by independent laboratories. The bar cross sectional area is gripped in the jaws of the testing machine and subjected to a tensile force increasing at a set rate. The test machine measures the displacement as force is applied, and the bar is extended to destruction as shown in Figure 4.

The test process is fundamental in understanding the mechanical properties of the material and controlling the quality of the bar received.

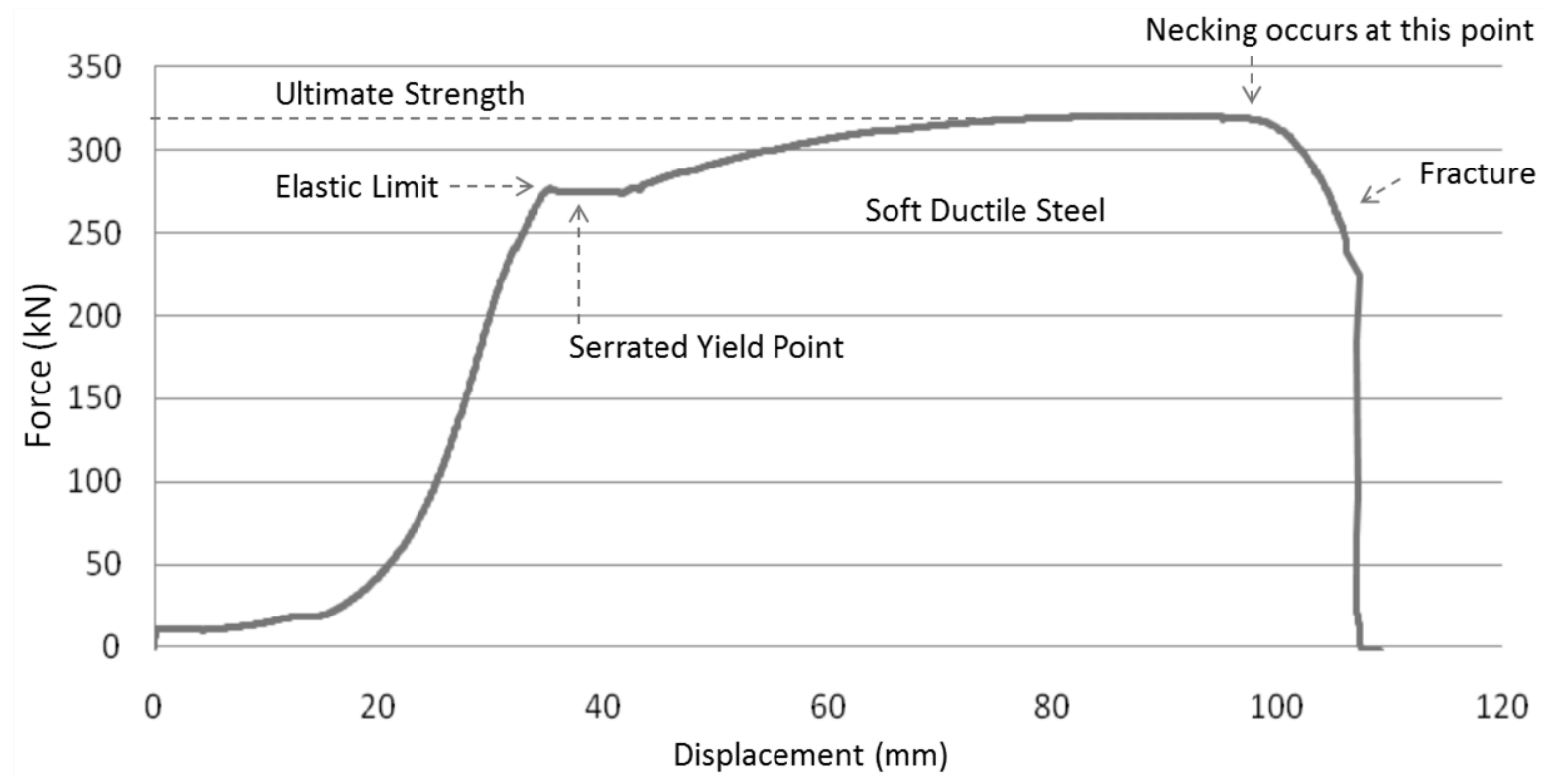

Figure 4 The JTech bolt tensile testing force-displacement graph

When bar is received, tensile testing is completed on every heat and batch number, ensuring the bar meets or exceeds specifications. The JTech bar specification is shown in Table 1 (Jennmar et al., 2013). 
Table 1 The JTech bolt specifications

\begin{tabular}{|c|c|c|c|c|c|}
\hline \multirow[t]{2}{*}{ Description } & \multicolumn{2}{|c|}{$\begin{array}{c}25 \mathrm{~mm} \text { Bar Properties } \\
\text { Minimum }\end{array}$} & \multicolumn{2}{|c|}{$\begin{array}{c}25 \mathrm{~mm} \text { Bar Properties } \\
\text { Typical }\end{array}$} & \multirow[t]{2}{*}{$\begin{array}{c}\text { Genera } \\
\text { Data }\end{array}$} \\
\hline & $\mathrm{MPa}$ & kN & $\mathrm{MPa}$ & kN & \\
\hline Yield strength of steel & 500 & 215 & 565 & 245 & \\
\hline Tensile strength of steel & 600 & 260 & 685 & 294 & \\
\hline Standard elongation & Min & $15 \%$ & Typ & $20 \%$ & \\
\hline Shear strength $(0.7 \times$ UTS $)$ & & 182 & & 201 & \\
\hline Bar diameter (mm) & Core & $23 \mathrm{~mm}$ & Major & $25 \mathrm{~mm}$ & \\
\hline Cross sectional area $\left(\mathrm{mm}^{3}\right)$ & & & & & 433 \\
\hline Mass per metre $(\mathrm{kg} / \mathrm{m})$ & & & & & 3.4 \\
\hline Drillhole size shredder $(\mathrm{mm})$ & & & & & $36-40$ \\
\hline Drillhole size paddle (mm) & & & & & $32-38$ \\
\hline \multicolumn{6}{|c|}{ Bar straightness to AS $1442-1991$} \\
\hline
\end{tabular}

\subsection{In situ testing of the JTech bolt, Kanga plate and JTech nut}

In situ testing is completed on the JTech Bolt system. The process involves pulling the JTech Bolt and nut through the Kanga Plate, over a $50 \mathrm{~mm}$ hole with results shown in Figure 5 . The test shows how the system performs when the load is applied to the $1,200 \mathrm{~mm}$ JTech bolt, Kanga plate and the JTech nut. A $50 \mathrm{~mm}$ hole in the test ring is selected to simulate a drill hole size in rock or fibrecrete.
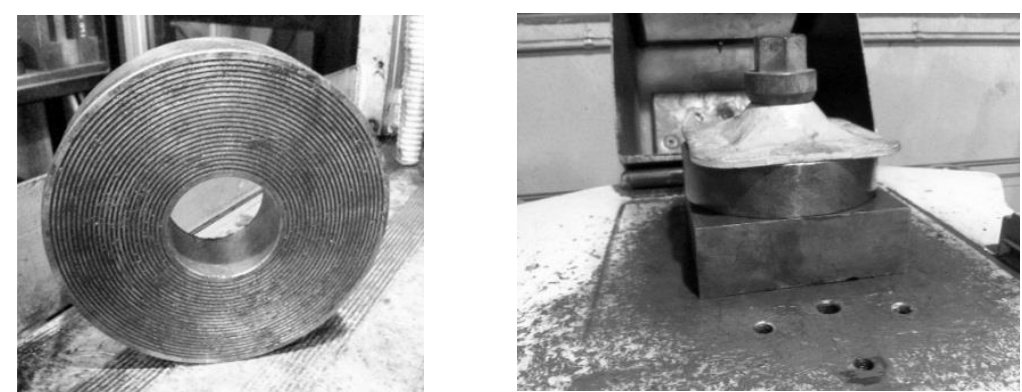

(a)
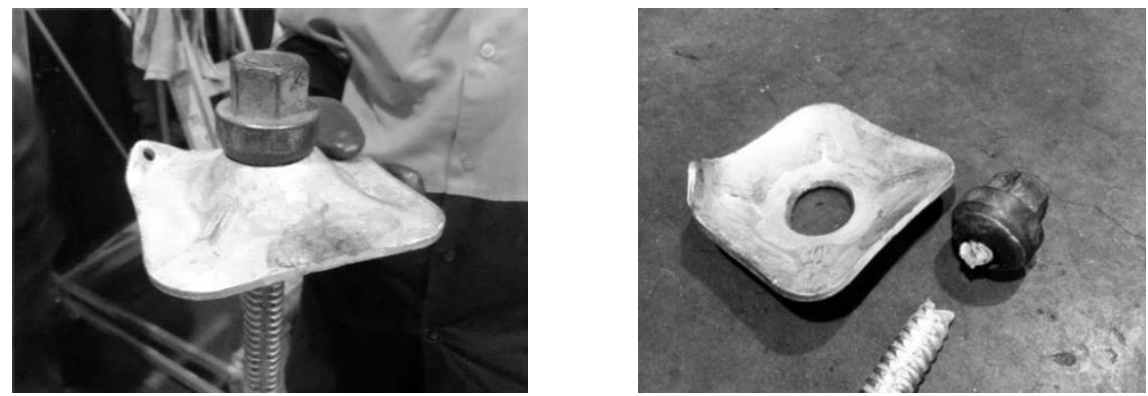

(b) 


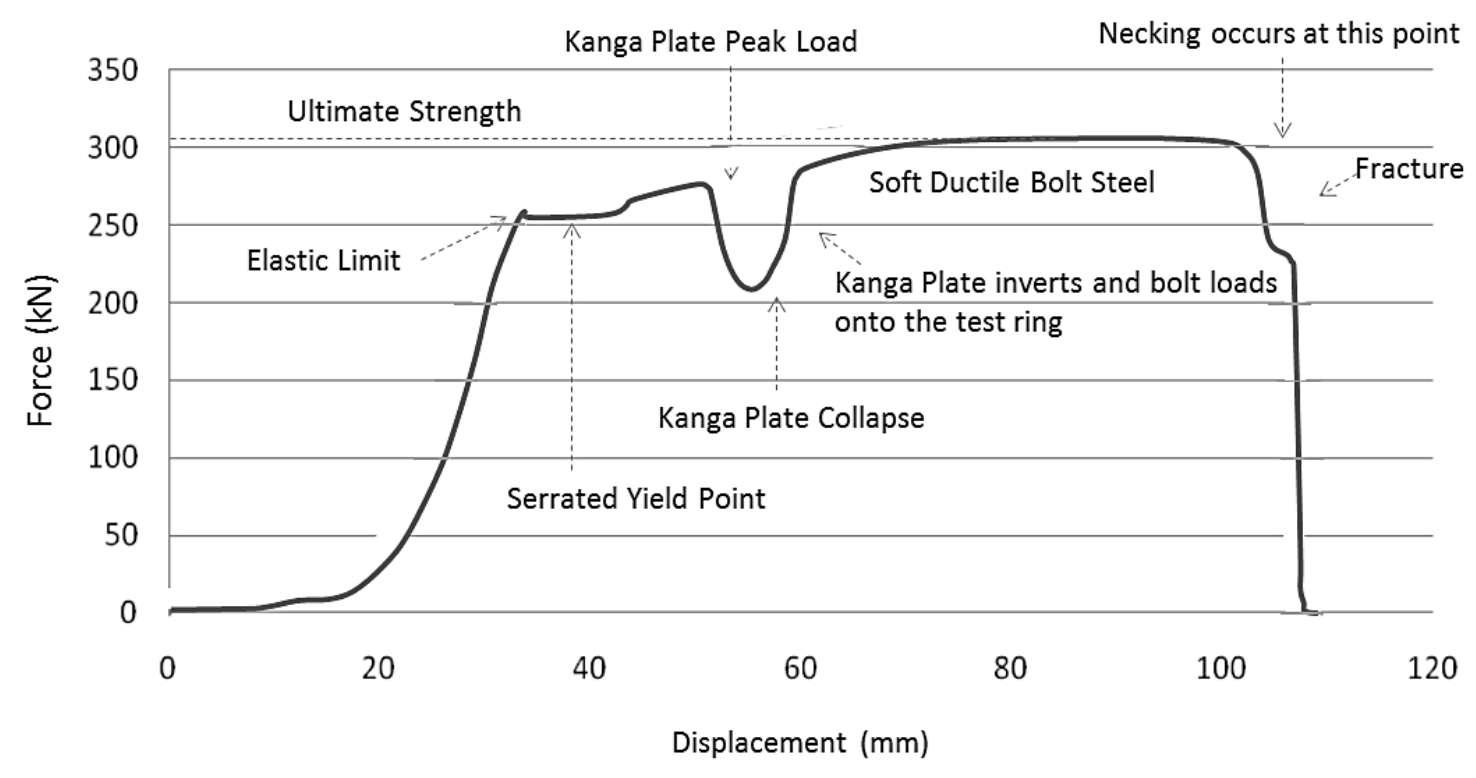

(c)

Figure 5 The Kanga Plate is designed to collapse at $25 \mathrm{t}$ which is the typical bar yield. The Kanga plate collapses into the hole and the bar loads up again against the test ring until bar failure; (a) $50 \mathrm{~mm}$ hole test ring, and a 1,200 mm JTech bolt, set up to pull the JTech bolt through the Kanga plate and $50 \mathrm{~mm}$ test ring. Before and after test images showing the assembled JTech bolt and Kanga plate system testing to destruction. Necking and bar failure is shown protruding from the JTech nut next to the collapsed Kanga plate; (c) force-displacement graph of the JTech bolt pulling through the Kanga Plate to destruction

\subsection{Double shear testing of the JTech bolt}

Double shear testing was conducted to gauge how the bolt may perform when shear loading conditions are evident in softer rock. The test process was completed to closely represent the interaction of the JTech bolt and rockmass across shear planes, which influence support stability in many hard rock mines. The test process involved preparing $230 \mathrm{~mm}^{3}$ concrete blocks, cast using an $80 \mathrm{MPa}$ mix design. The concrete blocks are cast with a $38 \mathrm{~mm}$ hole through the centre and placed in water to cure for 28 days. The cast blocks are located into the test frame, aligned and the JTech bar is set into the $80 \mathrm{MPa}$ blocks, and the bolt is pretensioned to $5 \mathrm{t}$, clamping the blocks together. The bar is centralised in the hole and low viscosity JLok resin is premixed and injected into the blocks to encapsulate the bar. Figure 6 shows the method of testing. 


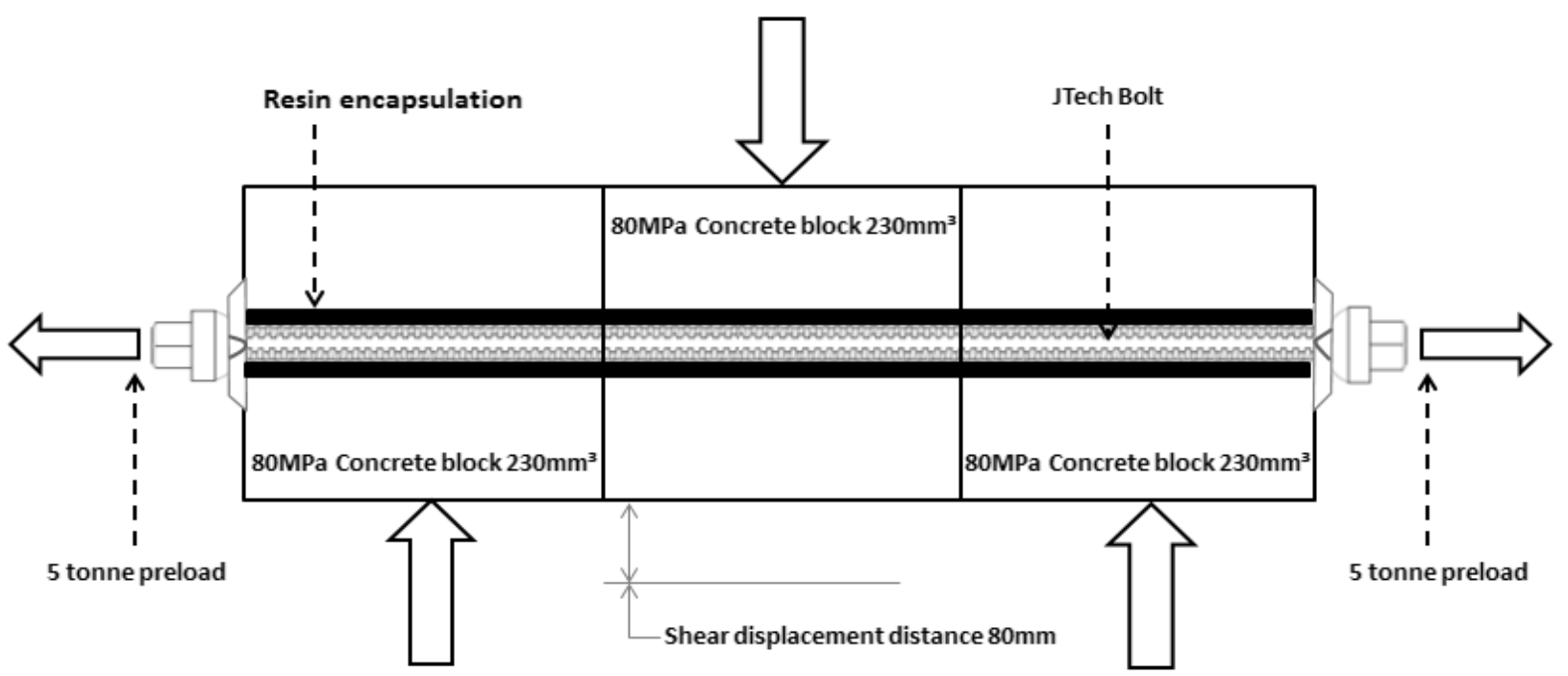

Figure 6 Cast $80 \mathrm{MPa}$ concrete block test diagram. The low viscosity resin is injected into the blocks to encapsulate the JTech bar and the blocks are clamped with $5 \mathrm{t}$ of preload

The resin is left to cure for 24 hours and the preassembled test frame, with the concrete blocks and JTech bar, is set into the $100 \mathrm{t}$ test machine. Testing of the bolt in shear is then conducted at a rate of $0.5 \mathrm{~mm} /$ minute, monitoring the vertical load until failure. Figure 7 shows the results of double shear testing of the JTech bar.

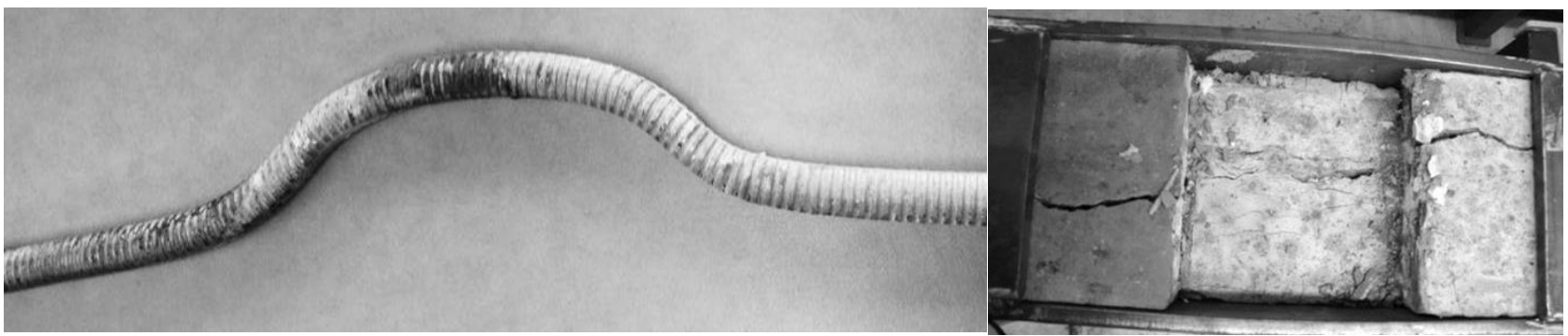

Figure 7 The JTech bar showing significant bending after it was removed from the concrete blocks. Resin bond was completely damaged from the test process. The concrete blocks were damaged significantly during the test as shown

Results vary depending on the test velocity, block strength and material type. The results shown in the Figure 8 force-displacement graph showed a test capacity of $80 \mathrm{t}$ was achieved in double shear, or $42.5 \mathrm{t}$ in single shear, when the concrete block bottomed out on the test bed and testing was aborted. There appears to be accumulative frictional forces from the shear planes increasing the load $12.5 \mathrm{t}$ greater than the bars typical tensile capacity. Due to testing being completed with simulated low rock strength, the zone across the shear planes is weaker, inducing a longer crushing length across the plane of weakness. A stiffer and stronger simulated rock material will fail with lower shear strengths. 


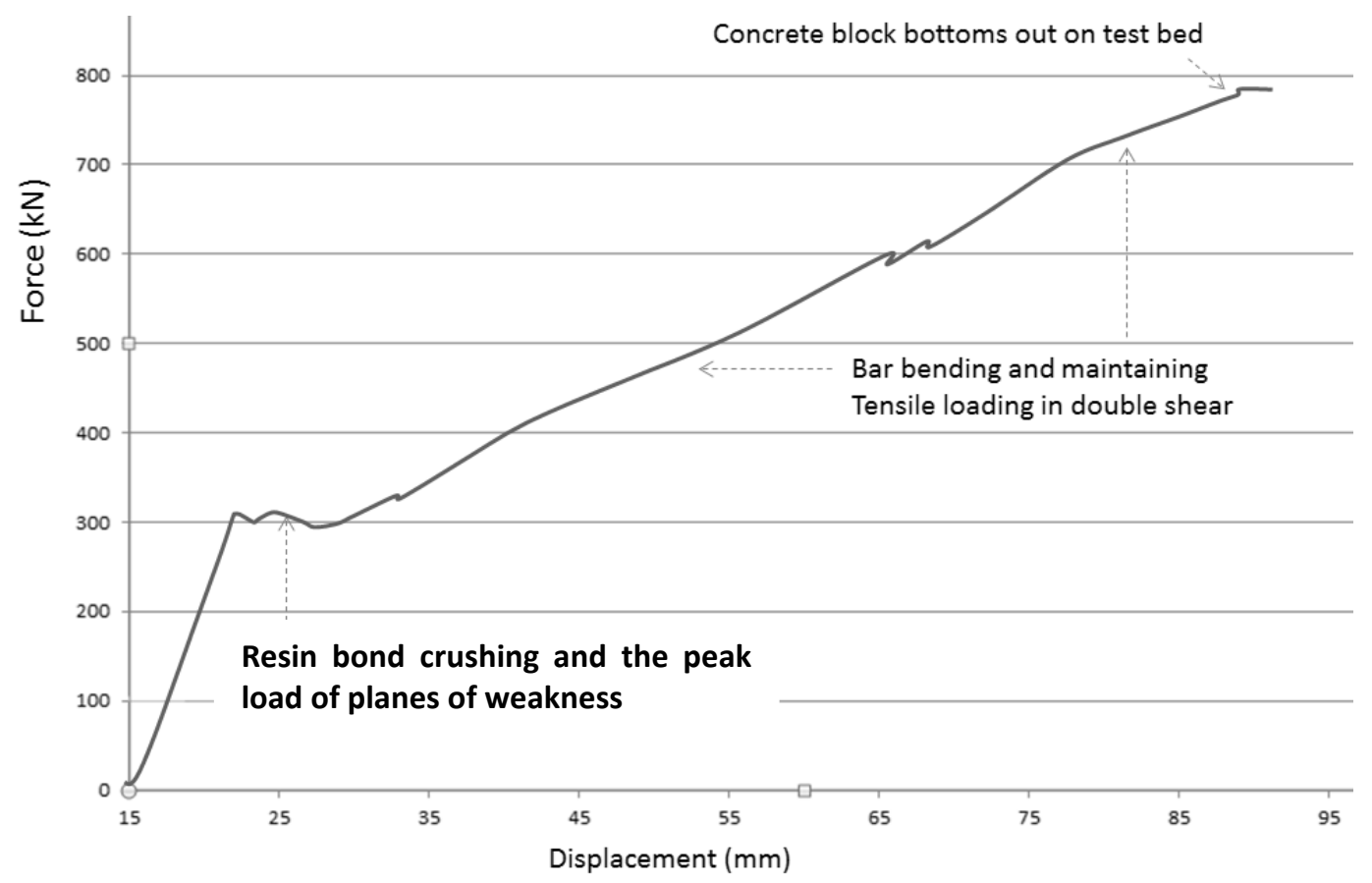

Figure 8 Force-displacement graph showing resin bond crushing and friction peak load across the planes of weakness at $30 \mathrm{t}$ and linear loading to $85 \mathrm{t}$, when the concrete block bottomed out on the test bed

The results in Figure 8 show a stiff system. Pre-tension of the JTech bolt to $5 \mathrm{t}$ increases system stiffness, and friction peak loads on the planes of weakness to $30 \mathrm{t}$. Constant loading at a reduced stiffness is shown to $80 \mathrm{t}$, as the JTech bar starts to apply load in a tensile failure mode with the combined frictional forces from the planes of weakness. The results indicate that the JTech bolt can withstand significant shear loading and displacement before failure in softer rock.

\subsection{JTech bolt and JLok resin mixing}

The JTech bar uses two resin mixing devices. A process was completed to confirm the JLok resin mixing capabilities of the following mixing devices:

1. Patented attachable device 'resin shredder'.

2. Mixing paddle.

The mixing devices were trialled and designed in laboratory conditions with successful results. Of the two mixing devices, the 'resin shredder' showed vastly improved resin mixing compared to the paddle bolt. Improved resin mixing, achieved by the shredder design, catching the JLok resin cartridge film, pushes the cartridge film to the back of the hole eliminating gloving, and ensured both catalyst and mastic cartridges are mixed homogeneously. Trials to evaluate $26 \mathrm{~mm}$ JLok resin cartridge mixing in 34.4 and $36 \mathrm{~mm}$ hole sizes at 2.3 and $2.9 \mathrm{~m}$ tube lengths were conducted to confirm resin mixing in general mining conditions. These two sizes relate to the drill bit size measured on Jumbo rigs when 33 and $35 \mathrm{~mm}$ drill bits are used. The installation provides the following data in general operating conditions:

- JLok Resin mixing results.

- Installation with Jumbo operators.

- Trialled with expected rotation RPM and feed rates.

- Trialled in underground temperature. 
- Installed in sidewalls with higher friction loads from the bolt rubbing on the hole during installation.

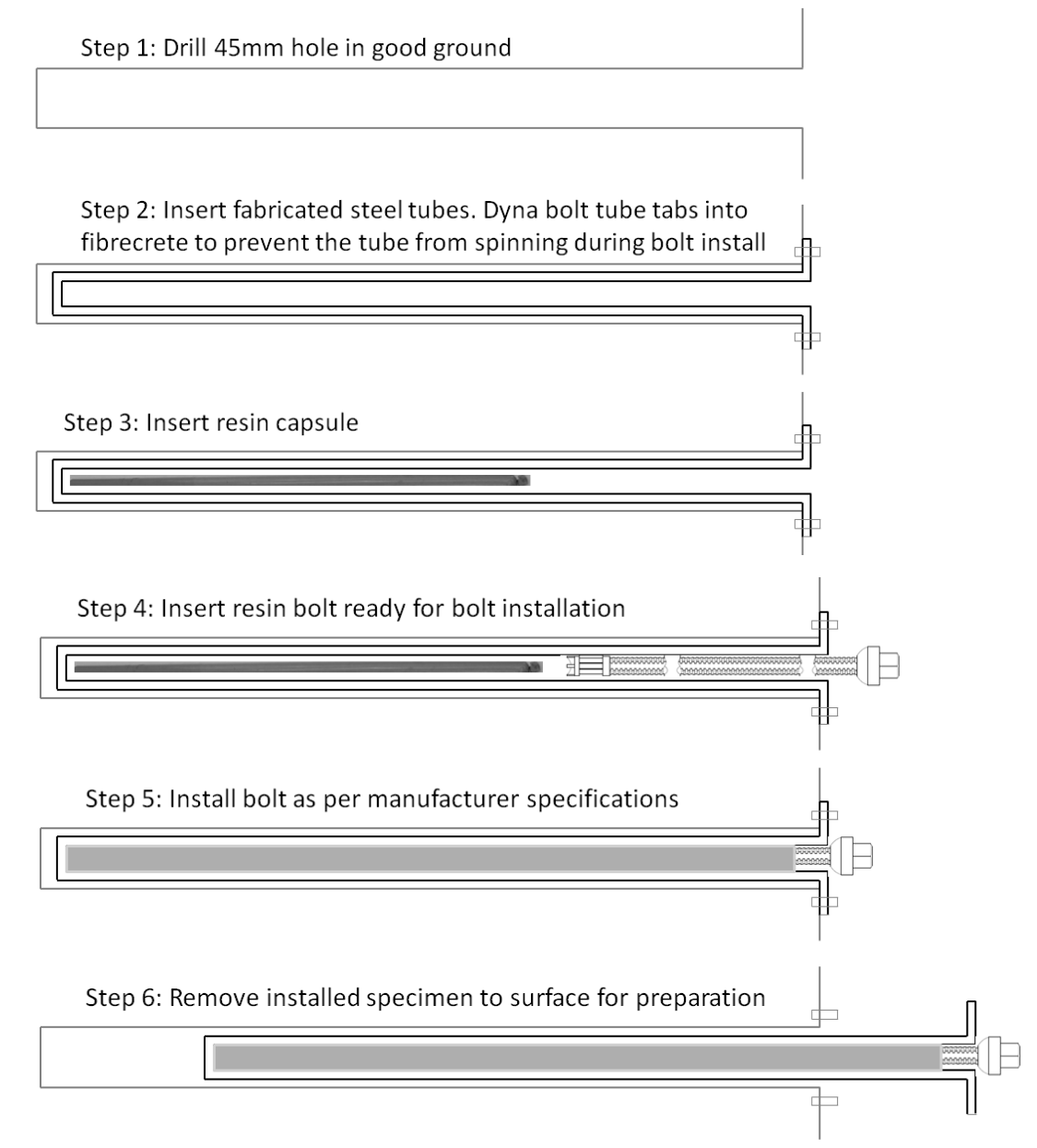

Figure 9 Steps one to six of the installation and JLok resin mixing process

Once the installation process shown in Figure 9 is complete, the tubes were removed and separated along the axis of the tube revealing the following results:

- JLok resin mixing achieved.

- Whether there has been homogenous mixing of resin.

- Potential bolt gloving.

- If the resin capsule has been pushed to the back of the hole.

- How the resin capsule film was shredded.

- Resin surrounding the bolt.

- Over mixed or under mixing of resin.

- Air pockets throughout the encapsulated length after resin mixing. 


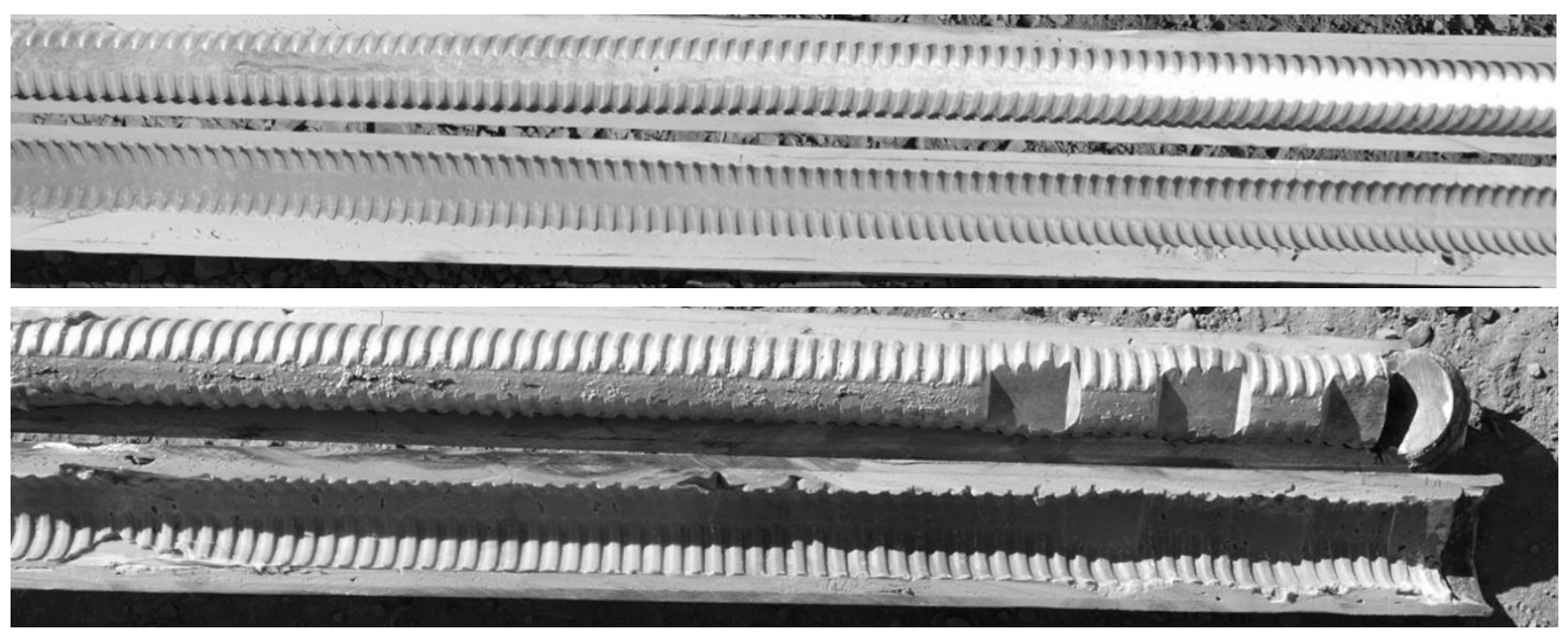

(a)
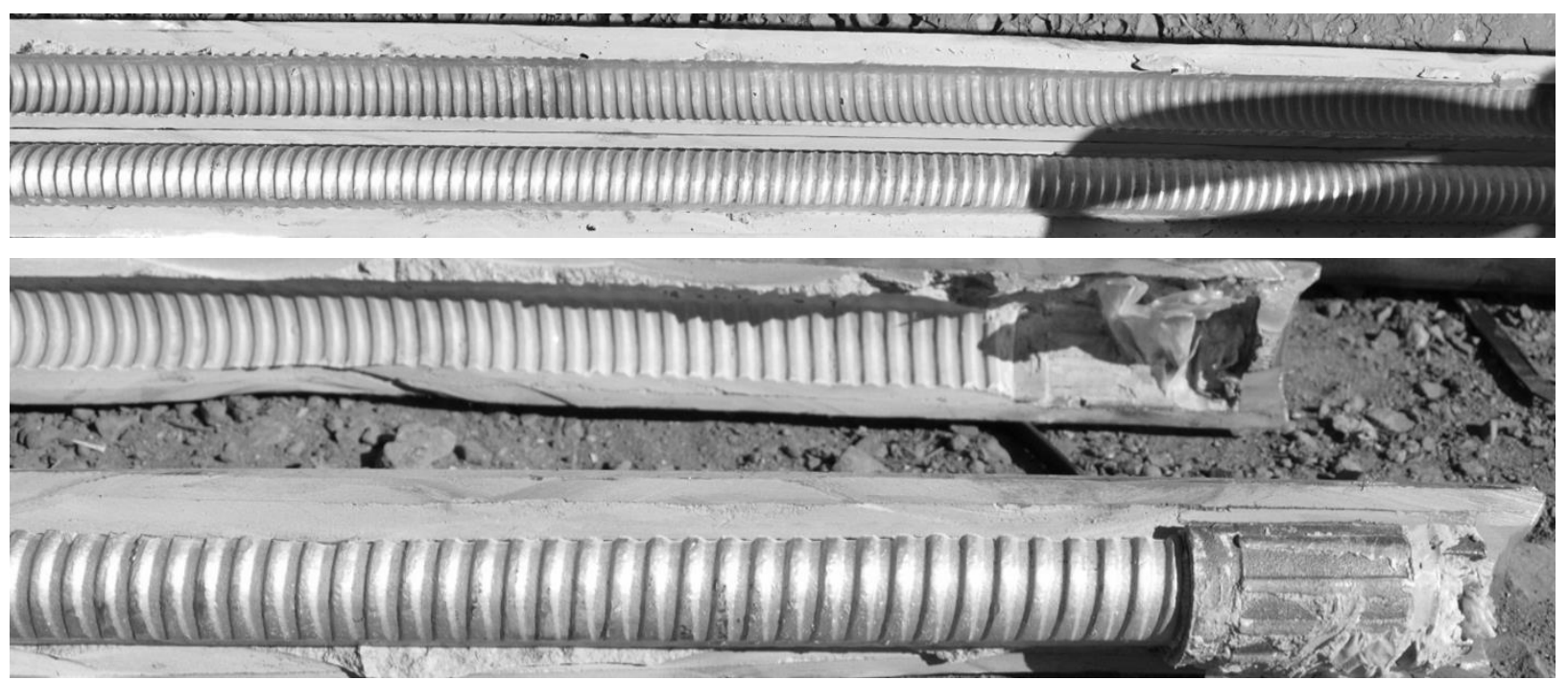

(b)

Figure 10 Resin mixing results from testing completed (a) One example of the resin mixing completed using the paddle mixing device (b) One example of the resin mixing completed using the resin shredder mixing

The resin mixing, shown in Figure 10, produced homogeneous resin mixing in both hole sizes and tube lengths. The resin shredder pushed the resin cartridge film to the back of the hole, which should eliminate potential bolt gloving. The paddled JTech bolt showed evidence of the resin cartridge film being mixed throughout the resin column. Limited air pockets were found in the samples completed, shown in Figure 10(a).

\subsection{JTech bolt and JLok resin laboratory testing}

Nine JTech bolts were installed into manufactured single embedment tubes, and fully encapsulated using JLok resin capsules in the laboratory to control the installation process. To achieve this, the tube is cut and sealed at one end and rubbed internally with sand paper to clean and roughen the internal bore of the tube, to ensure the resin bonds to the tube surface. The prepared tube is set into a lathe pedestal and fixed into position. A section of the fast set end of the resin is then inserted into the reamed tube, and spun for 8 to 10 seconds, mixed at 210 RPM with left hand rotation, to replicate jumbo rig installation, then left to cure for no less than 1 hour. The sample preparation is shown in Figure 11. 


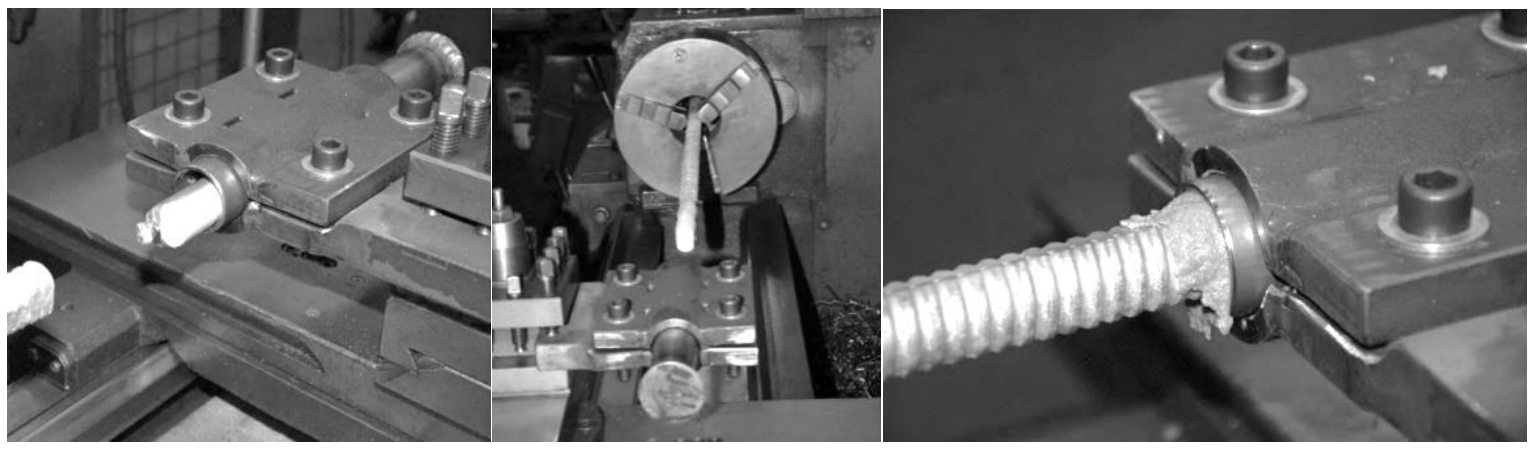

Figure 11 Test sample preparation

The one hour resin set time is to achieve an optimum resin strength (cure time). The completed JTech bolt samples are then fixed into the test machine, where the bolt or resin bond is loaded to failure, measuring the load and displacement shown in Figure 12. Product, test lengths and results achieved for each test are shown in Table 2:

Table 2 Bolt type, tube length, resin capsule length and test loads

\begin{tabular}{ccccc}
\hline Bolt & Bolt Type & Tube Length & Resin Capsule & Load Achieved (kN) \\
\hline 1 & $300 \mathrm{kN} 25 \mathrm{~mm}$ JTech bolt $\times 1200 \mathrm{~mm}$ & $300 \mathrm{~mm}$ & JLok $300 \times 26 \mathrm{~mm}$ & 245.6 abort test \\
2 & $300 \mathrm{kN} 25 \mathrm{~mm}$ JTech bolt $\times 1200 \mathrm{~mm}$ & $300 \mathrm{~mm}$ & JLok $300 \times 26 \mathrm{~mm}$ & 299.1 broke bar \\
3 & $300 \mathrm{kN} 25 \mathrm{~mm} \mathrm{JTech}$ bolt $\times 1200 \mathrm{~mm}$ & $300 \mathrm{~mm}$ & JLok $300 \times 26 \mathrm{~mm}$ & 299.7 max travel \\
4 & $300 \mathrm{kN} 25 \mathrm{~mm}$ JTech bolt $\times 1200 \mathrm{~mm}$ & $400 \mathrm{~mm}$ & JLok $400 \times 26 \mathrm{~mm}$ & 287.9 max travel \\
5 & $300 \mathrm{kN} 25 \mathrm{~mm}$ JTech bolt $\times 1200 \mathrm{~mm}$ & $400 \mathrm{~mm}$ & JLok $400 \times 26 \mathrm{~mm}$ & 299.0 broke bar \\
6 & $300 \mathrm{kN} 25 \mathrm{~mm} \mathrm{JTech} \mathrm{bolt} \times 1200 \mathrm{~mm}$ & $400 \mathrm{~mm}$ & JLok $400 \times 26 \mathrm{~mm}$ & 299.3 broke bar \\
7 & $300 \mathrm{kN} 25 \mathrm{~mm}$ JTech bolt $\times 1200 \mathrm{~mm}$ & $500 \mathrm{~mm}$ & JLok $500 \times 26 \mathrm{~mm}$ & 289.0 broke bar \\
8 & $300 \mathrm{kN} 25 \mathrm{~mm}$ JTech bolt $\times 1200 \mathrm{~mm}$ & $500 \mathrm{~mm}$ & JLok $500 \times 26 \mathrm{~mm}$ & 299.9 broke bar \\
9 & $300 \mathrm{kN} 25 \mathrm{~mm} \mathrm{JTech} \mathrm{bolt} \times 1200 \mathrm{~mm}$ & $500 \mathrm{~mm}$ & JLok $500 \times 26 \mathrm{~mm}$ & 299.8 broke bar \\
\hline
\end{tabular}




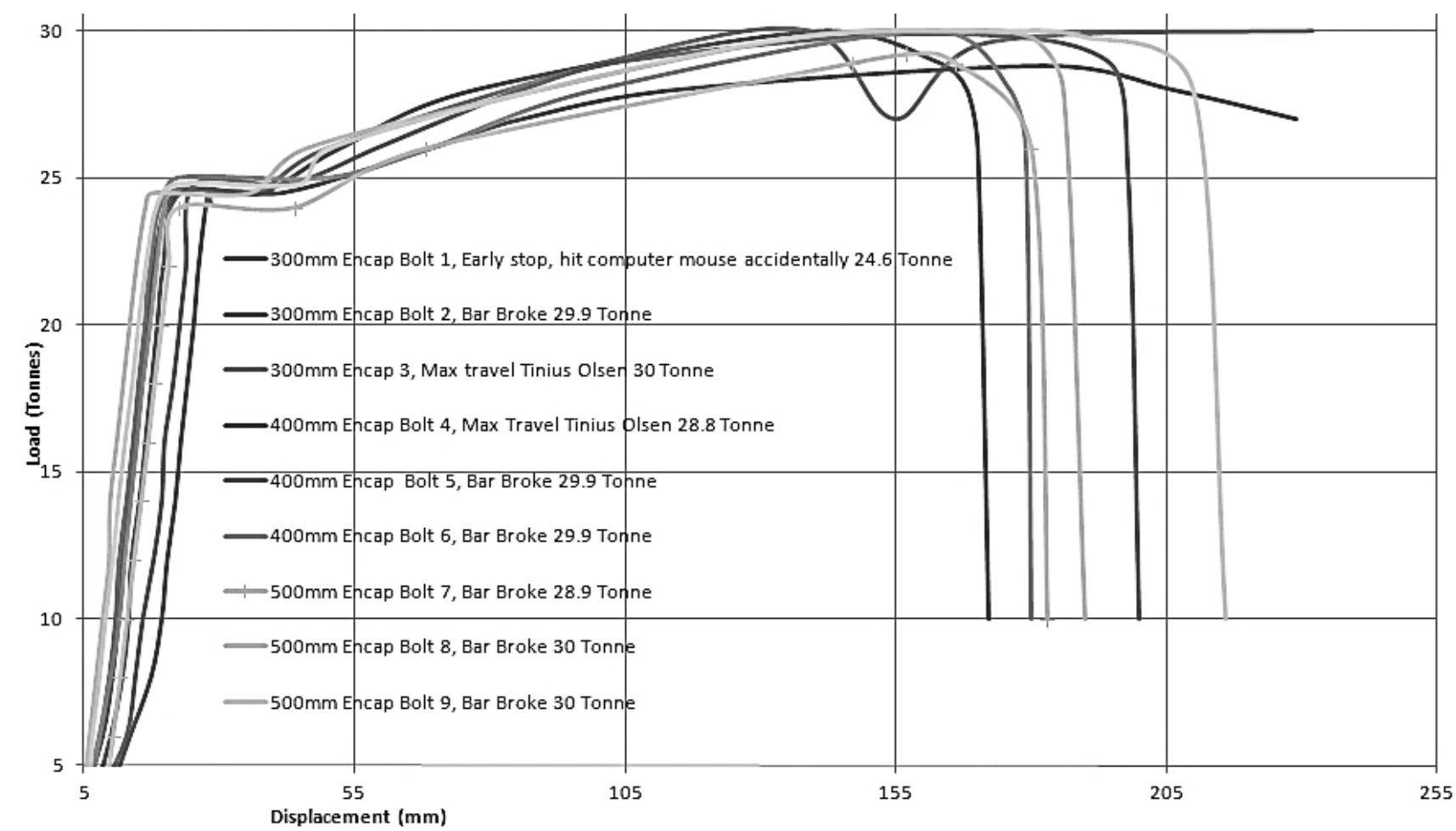

Figure 12 Load/displacement results for the nine JTech bolt short encapsulation laboratory testing

The test results, shown in Figure 12, have produced consistent and reliable results with six of the nine bolt tests breaking the bar. These six test results, one $300 \mathrm{~mm}$ encapsulation, two $400 \mathrm{~mm}$ encapsulation, and three $500 \mathrm{~mm}$ encapsulation lengths, induced no failure to the resin bond, and replicate the force-displacement curves shown in Figure 4. Two bolts, one $300 \mathrm{~mm}$ encapsulation and one $400 \mathrm{~mm}$ encapsulation lengths, reached close to bar ultimate tensile strength. The curves look similar to a force-displacement curve with one exception; the resin bond starts to fail around the bar, with the bolt displacing until the test machine bottoms out and the test is stopped. The last $300 \mathrm{~mm}$ encapsulated bolt test was aborted, due to accidentally hitting the mouse on the test machine prior to the bar going into yield.

When conducting short encapsulation tests, the bond strength of a resin bolt is a fundamental parameter in determining the effectiveness of the resin mixing device, and resin shear across the bolt pitch. The stronger the bond, the shorter the anchorage zone of the bolt is required to reach the ultimate tensile strength of the bar, and resist ground movement.

Using a resin anchored system, the anchorage provided by the resin is related to the length of the bond and the bond strength, and can easily exceed the strength of the steel. For this reason, a specifically installed bolt with a shorter length of resin encapsulation is required to measure the bond strength of the resin anchor, or rock shear strength rather than the strength of the bolt.

When conducting short encapsulation testing, the bond strength, contact shear strength, and the system stiffness can be calculated as follows (results shown in Table 3 ):

$$
\begin{gathered}
\text { Bond strength }(B S)=\frac{F}{l}[\mathrm{kN} / \mathrm{mm}] \\
\text { Contact shear strength }(\tau)=\frac{F}{\pi d l}[\mathrm{kPa}] \\
\text { System stiffness }(k)=\frac{\Delta \mathrm{F}}{\Delta D}[\mathrm{kN} / \mathrm{mm}]
\end{gathered}
$$


Where:

$F \quad=\quad$ load at slippage $(\mathrm{kN})$.

$\Delta F \quad=\quad$ change in force $(\mathrm{kN})$.

$\Delta D=\quad$ change in deformation $(\mathrm{mm})$.

I = anchorage length $(\mathrm{mm})$.

$d=\quad$ hole diameter $(\mathrm{mm})$.

Table 3 System stiffness, contact shear strength and bond strengths

\begin{tabular}{cccc}
\hline Bolt \# & System Stiffness $(\mathbf{k N} / \mathbf{m m})$ & Contact Shear Strength $(\mathbf{k P a})$ & Bond Strength $(\mathbf{k N} / \mathbf{m m})$ \\
\hline 1 & 17.5 & 7.8 & 0.82 \\
2 & 18.7 & 9.4 & 1.00 \\
3 & 18.4 & 9.5 & 1.00 \\
4 & 15.8 & 6.8 & 0.72 \\
5 & 15.9 & 7.1 & 0.75 \\
6 & 15.7 & 7.1 & 0.75 \\
7 & 15.7 & 5.5 & 0.58 \\
8 & 17.6 & 5.7 & 0.60 \\
9 & 15.3 & 5.7 & 0.60 \\
\hline
\end{tabular}

A significant amount of underground pull-out testing has been completed to meet normal mine site quality control test requirements. Short encapsulation testing underground has been completed in varying ground conditions and rock strengths producing similar results to the lab testing completed.

\subsection{JTech bolt dynamic testing}

Dynamic testing was conducted on three JTech bolts using $30 \mathrm{~mm}$ JLok resin capsules at the CANMET drop test facility shown in Figure 13. The test facility consists of a loading frame made of two columns $4.91 \mathrm{~m}$ high, $28 \mathrm{~cm}$ in diameter and $1.18 \mathrm{~m}$ apart, topped by a horizontal cross-beam, with two hoists for lifting the drop weight and electro-magnet, and adjusting the test height. The system has a rated capacity of $3 \mathrm{Mt}$ at maximum drop height of two metres for a maximum velocity of $6.26 \mathrm{~m} / \mathrm{s}$, and energy input at impact of $58.8 \mathrm{~kJ}$. Load and displacement measurements are recorded through a data acquisition system (Plouff et al., 2008).

Loads are measured on both ends of the test assembly, for example the holding tube and impact location, or bottom plate. Displacements are measured optically, with linescan cameras installed at both ends of the test specimen. Strain gauges are also installed on the testing frame columns and cross-beam, to monitor energy losses during testing. These are estimated to be less than $1 \%$, and usually neglected during the results calculation (Anderson, 2008). 

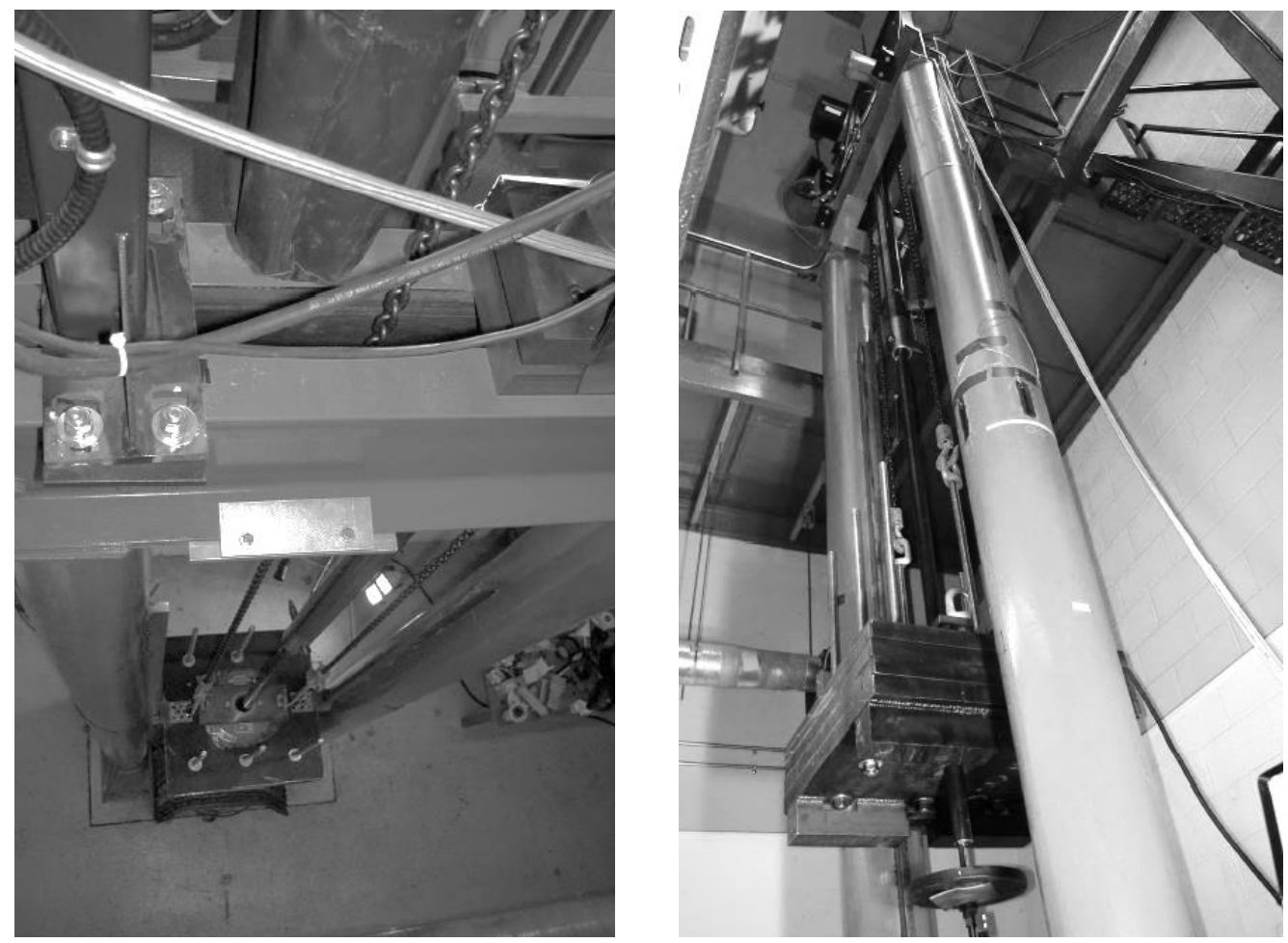

\section{Figure 13 Drop test facility}

Failed specimens are indicated by the dark grey cells shown in Table 4 and 5 . Test results are presented graphically, showing the complete displacement, and load behaviour during, and at the end of each test shown in Figure 14. The input (or impact) energy $(E$, in $\mathrm{kJ})$ and velocity $(V$, in $\mathrm{m} / \mathrm{s})$ are calculated as follows:

$$
\begin{aligned}
& E=\frac{m h g}{1000} \\
& V=\sqrt{2 g h}
\end{aligned}
$$

Where:

$$
\begin{array}{ll}
m & =\text { drop mass, in } \mathrm{kg} . \\
h & =\text { drop height, in } \mathrm{m} . \\
g & =\quad \text { gravitational acceleration, i.e. } 9.81\left(\mathrm{~m} / \mathrm{s}^{2}\right) .
\end{array}
$$

Both lower plate and upper (top) end displacements are continuously recorded during each test (with several impacts). Values are extracted from the data file once the load on the test specimen has stabilised and returned to zero. Manual measurements of both lower plate and upper end displacements are made and recorded after each impact. The steel stretch plastic is the amount of stretching of the bolt given by the difference between the lower plate and upper end displacement measurements. Load and deformation values are extracted from load versus plate displacement, and load versus time graphs plotted after each impact, and at the end of each test. The peak load is the highest load recorded at the point of impact, and at the lower end (bottom plate) of the bolt upon impact, whereas the average load is the average value of the load recorded by load cells, at both the impact point and the lower end plate during the test. The total elongation is obtained by measuring the length of the bolt after failure, and subtracting it from the initial bolt length. The steel stretch for the last impact in this case is calculated by subtracting the steel stretch measured after the previous impacts, from the total elongation measured after failure. The absorbed energy is the area under the load-plate displacement curve. Test results are shown in Tables 4 and 5. 
Table 4 Dynamic Test 1 (JEN 3)

\begin{tabular}{|c|c|c|c|c|c|c|c|c|c|c|}
\hline $\begin{array}{c}\text { Drop } \\
\#\end{array}$ & $\begin{array}{c}\text { Drop } \\
\text { Mass } \\
\text { (kg) }\end{array}$ & $\begin{array}{l}\text { Drop } \\
\text { Height } \\
\text { (m) }\end{array}$ & $\begin{array}{c}\text { Input } \\
\text { Energy } \\
\text { (kJ) }\end{array}$ & $\begin{array}{c}\text { Impact } \\
\text { Velocity } \\
\text { (m/s) }\end{array}$ & $\begin{array}{c}\text { Plate } \\
\text { Displ. } \\
\text { (m) }\end{array}$ & $\begin{array}{c}\text { Top } \\
\text { Displ. } \\
\text { (m) }\end{array}$ & $\begin{array}{c}\text { Steel } \\
\text { Stretch } \\
\text { Plastic (m) }\end{array}$ & $\begin{array}{l}\text { Yield } \\
\text { Load } \\
\text { (kN) }\end{array}$ & $\begin{array}{l}\text { Ave } \\
\text { Load } \\
(\mathrm{kN})\end{array}$ & $\begin{array}{c}\text { Absorbed } \\
\text { Energy } \\
\text { (kJ) }\end{array}$ \\
\hline 1 & 1,115 & 1.50 & 16.41 & 5.42 & 0.042 & 0.000 & 0.042 & 271 & 201 & - \\
\hline 2 & 1,115 & 1.50 & 16.41 & 5.42 & 0.046 & 0.000 & 0.046 & 300 & 219 & 11 \\
\hline 3 & 1,115 & 1.50 & 16.41 & 5.42 & 0.096 & 0.078 & 0.018 & 254 & 230 & 13 \\
\hline 4 & 1,115 & 1.50 & 16.41 & 5.42 & 0.168 & 0.167 & 0.001 & 265 & 75 & 14 \\
\hline 5 & 1,115 & 1.50 & 16.41 & 5.42 & 0.045 & 0.000 & 0.045 & 300 & 300 & 15 \\
\hline 6 & 1,115 & 1.50 & 16.41 & 5.42 & 0.039 & 0.000 & 0.039 & 250 & 240 & 11 \\
\hline 7 & 1,115 & 1.50 & 16.41 & 5.42 & 0.041 & 0.000 & 0.041 & 285 & 275 & 11 \\
\hline 8 & 1,115 & 1.50 & 16.41 & 5.42 & 0.042 & 0.000 & 0.042 & 312 & 295 & - \\
\hline 9 & 1,115 & 1.50 & 16.41 & 5.42 & 0.036 & 0.000 & 0.038 & 310 & 290 & Failed \\
\hline
\end{tabular}

Table 5 Drop test results JTech bolt 2 (JEN 4) and JTech bolt 3 (JEN 5)

\begin{tabular}{ccccccccccc}
\hline $\begin{array}{c}\text { Drop } \\
\#\end{array}$ & $\begin{array}{c}\text { Drop } \\
\text { Mass } \\
(\mathbf{k g})\end{array}$ & $\begin{array}{c}\text { Drop } \\
\text { Height } \\
(\mathbf{m})\end{array}$ & $\begin{array}{c}\text { Input } \\
\text { Energy } \\
\mathbf{( k J )}\end{array}$ & $\begin{array}{c}\text { Impact } \\
\text { Velocity } \\
(\mathbf{m} / \mathbf{s})\end{array}$ & $\begin{array}{c}\text { Plate } \\
\text { Displ. } \\
\mathbf{( m )}\end{array}$ & $\begin{array}{c}\text { Top } \\
\text { Displ. } \\
\mathbf{( m )}\end{array}$ & $\begin{array}{c}\text { Steel } \\
\text { Stretch } \\
\text { Plastic } \\
(\mathbf{m})\end{array}$ & $\begin{array}{c}\text { Impact } \\
\text { Peak } \\
\text { Load } \\
(\mathbf{k N})\end{array}$ & $\begin{array}{c}\text { Ave } \\
\text { Load } \\
(\mathbf{k N})\end{array}$ & $\begin{array}{c}\text { Absorbed } \\
\text { Energy } \\
(\mathbf{k J})\end{array}$ \\
\hline 1 & 2,006 & 1.50 & 29.52 & 5.42 & 0.052 & 0.002 & 0.078 & 320 & 260 & 23.3 \\
\hline 2 & 2,006 & 1.50 & 29.52 & 5.42 & 0.000 & 0.000 & 0.074 & 315 & 290 & 28.8 \\
1 & 2,452 & 1.50 & 36.08 & 5.42 & 0.102 & 0.002 & 0.102 & 320 & 280 & 30.0 \\
\hline
\end{tabular}

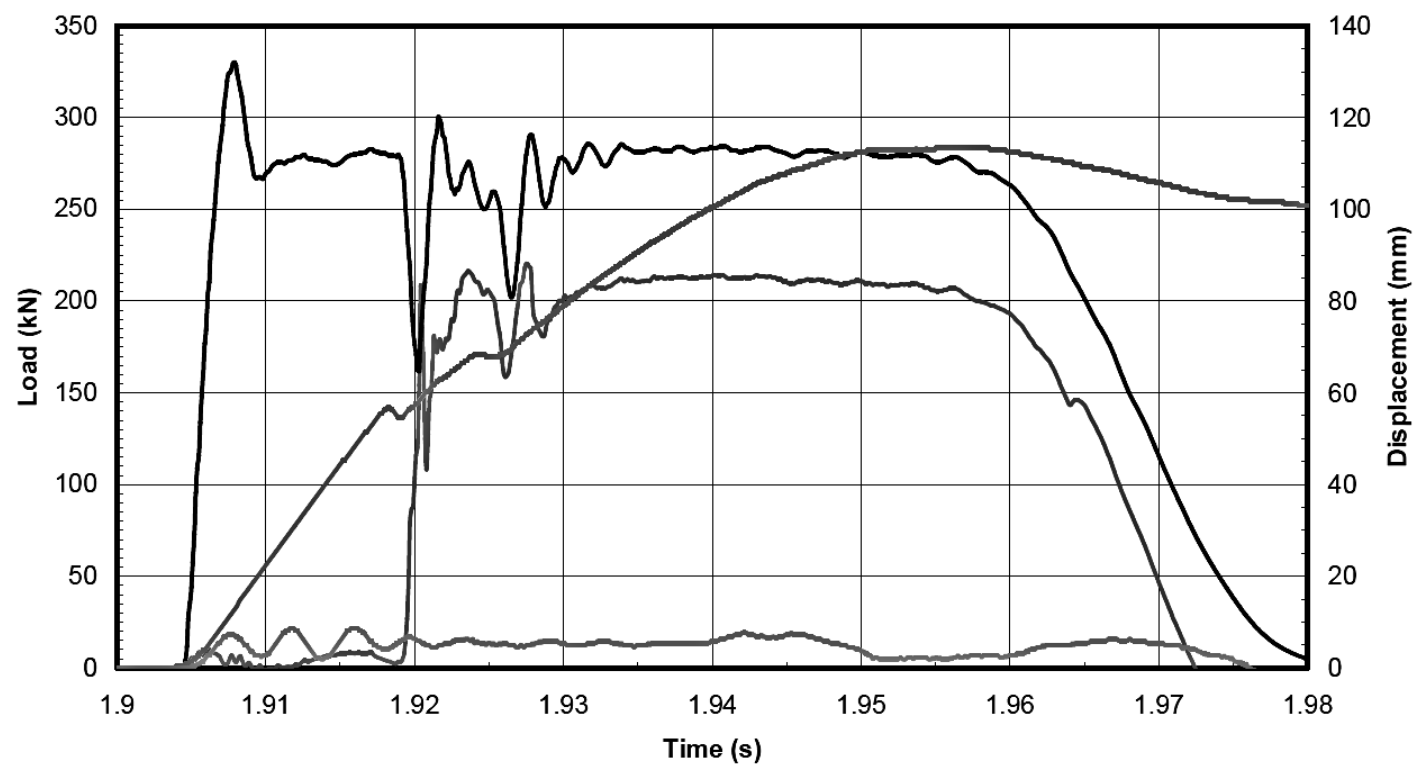

Figure 14 Dynamic test results showing load/time/displacement data for the test specimens bolt 2 (JEN 4) and bolt 3 (JEN 5) 
Table 4 shows JTech bolt 1 (JEN 3) results with a mass of $1,115 \mathrm{~kg}$, drop height of $1.5 \mathrm{~m}$, drop velocity of $5.42 \mathrm{~m} / \mathrm{s}$ and input energy of $16.41 \mathrm{~kJ}$. JEN 3 required nine impacts to fail the bolt. JEN 3 tests were completed using a $30 \mathrm{~mm}$ JLok resin capsule mixed using a 2,095 mm JTech bolt, into a 1,900 $\mathrm{mm}$ single tube, with a $34.7 \mathrm{~mm}$ bore size. The bottom plate was secured using a Kanga plate, with a total steel stretch of $310 \mathrm{~mm}$ from the nine tests completed. Table 5 shows JTech bolt 2 (JEN 4) results with a mass of $2,006 \mathrm{~kg}$, drop height of $1.5 \mathrm{~m}$, drop velocity of $5.42 \mathrm{~m} / \mathrm{s}$ and input energy of $29.5 \mathrm{~kJ}$. JEN 4 required two drops to fail the bolt, with the first test withstanding the impact. The total steel stretch from both tests was $152 \mathrm{~mm}$. JTech bolt 3 (JEN 5) results shown in Figure 14, and Table 5, with a mass of 2,452 kg, drop height of $1.5 \mathrm{~m}$, drop velocity of $5.42 \mathrm{~m} / \mathrm{s}$ and input energy of $36.1 \mathrm{~kJ}$. JEN 5 was one drop in total which did not fail the bolt. The total steel stretch from the test was $102 \mathrm{~mm}$. The JTech bolt was not tested a second time as bolt failure was expected. Both JEN 4 and JEN 5 tests were completed using $30 \mathrm{~mm}$ JLok resin capsules, mixed using a 2,095 $\mathrm{mm}$ JTech bolt into a $1,900 \mathrm{~mm}$ split-tube with a $37.8 \mathrm{~mm}$ bore size. The bottom plate was secured using a Kanga plate.

\section{$4 \quad$ Conclusions}

The JTech bolt when used with a Kanga plate or equivalent high capacity plate provides the engineer with data in designing a support system, and understanding the 'weakest link' in the system. The JTech bolt has shown a capacity to absorb $30 \mathrm{~kJ}$ of input energy from a $36.1 \mathrm{~kJ}$ impact without failure; the JTech bolts' highest dynamic result. In situ static testing results show the bond strength of a resin bolt is fundamental in determining its effectiveness. The JTech bar has proven to provide high static capacity with limited bond length to resist ground movement. A $300 \mathrm{~mm}$ resin encapsulation length is exceeding the $30 \mathrm{t}$ typical ultimate tensile strength of the JTech bar.

The capacity of any excavation is dependent on the ground support system, the reinforcing element and combined surface system support to work together. By understanding the JTech bolt in situ capacity, designing a surface support system to fit the demand of a static, quasi-static or dynamic domains is achievable if the surface support capacity and their limitations are understood.

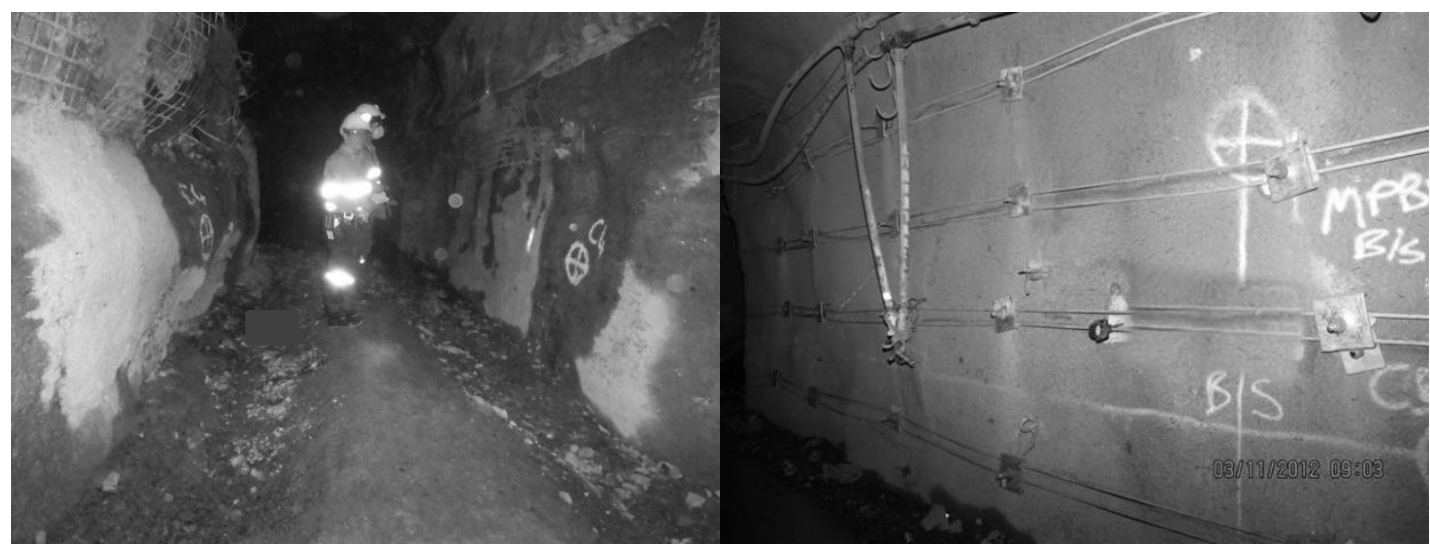

Figure $15 \mathrm{JTech}$ Bolt and surface support for squeezing ground

Figure 15 shows over a metre of convergence in each wall of a drive with significant floor heave. The JTech bolt works with a support system using fibrecrete, mesh, osro straps, and cable slings and through pillar support, to provide a high capacity, energy absorbing system, shown with cable slings installed at one metre spacing. The JTech bolt uses a plate to lace the cables through previously installed JTech bolts to confine the pillar and reinforce the mesh, osro strap and fibrecrete skin of the surface support. When installed in excavations with excessive convergence, the JTech bolt can still retain load carrying capacity, with up to one metre of closure, depending on the depth of failure around the drive, bolt length and allowable elongation of the JTech bar.

By working to continue to test and validate ground support systems, better understanding and confidence in the support design can be achieved by understanding the capacity of the complete support system. 


\section{References}

Anderson, T. (2008) Design guidelines for the dynamic behaviour of ground support tendons, WSIB/RAC, Bridging the Gap, Section III Facilities and Procedures, pp. 60-65.

ACRS Compliance (2007) ACRS Compliance: your Assurance of Quality for OneSteel Rebar and Reomesh Processing, viewed 28 January 2013, http://www.reinforcing.com/asset/cms/TECHNICAL RESOURCES/ACRS_Quality_Compliance.pdf.

Jennmar (2013) Hard Rock Catalogue, Jennmar Australia, viewed 28 January 2013, http://www.jennmar.com.au/pageflip/hardrock/hard-rock.html\#/1/.

Plouffe, M., Anderson, T. and Judge, K. (2008) Rock bolts testing under dynamic conditions at CANMET-MMSL, in Proceedings 6th International Symposium on Ground Support in Mining and Civil Construction, T.R. Stacey and D.F. Malan (eds), 30 March-3 April 2008, Cape Town, South Africa, The Southern African Institute of Mining and Metallurgy, Johannesburg, pp. 581-595. 
